\title{
Whisker Test Methods of JEITA Whisker Growth Mechanism for Test Methods
}

\author{
Ichizo Sakamoto \\ Chairman of JEITA whisker testing subcommittee \\ Japan Electronics and Information Technology Industries Association \\ Technical Standardization Committee on Electronics Assembly Technology, Japan \\ ( http://tsc.jeita.or.jp/TSC/COMMS/7_EASM/english/index.htm )
}

\section{Introduction}

There is an establishment of whisker test methods as one of issues of Lead-free electric device.

A Tin plating was used for a terminal plating of an electric device before. However, there is a problem of whiskers growth, and the Sn-Pb plating has been used mainly. A whisker is a Tin crystal, which grows up at time though is not seen in the early stage. It might be a causes of the short-circuit of the electric circuit, so that these test methods will be a key point for Lead-free technology.

Japanese government requested JEITA to establish test methods for solderability, reliability, whisker and migration for Lead-free. This subcommittee plan has a goal to propose the test methods by March 2004.

We carried out a literature survey, developed a hypotheses of relation between external stress and whiskers growth for the test methods. Moreover, we started two types of studies. One is a fundamental study to verify a hypothesis. Other is an acceleration study to decide test conditions.

As a result, we found that the diffusion of copper, the oxidation, and heat changing have influence with a whisker growth. Now, we have finished almost studies. At present, we ended the drafting of " Whisker growth mechanism " which becomes the base of the test methods. Moreover, we are drafting the test methods.

This time, we introduce our result of fundamental studies and report on "Whisker Growth Mechanism " of JEITA.

\section{Whisker Growth Mechanism}

Before the introduction of an experiment result, we explain "Whisker Growth Mechanism" as shown in Figure 1.

The frameworks of mechanism are as follows:

- $\quad$ First, There are three phases in Whisker Growth; Deposit design, Component design and Stress generated when using.

- Second, a whisker occurs by the recrystallization of tin, and grows depending on the compression stress in the deposit.

- $\quad$ Third, The stress is generated by internal stress of plating deposit, Cu6Sn5 diffusion, oxidization, and mechanical compression stress.

- $\quad$ Fourth, compression stresses to grow whisker exist with depend on component designs.

- $\quad$ Fifth, Cu3Sn diffusion decreases volume in Tin deposit, so that compression stress decrease.

- $\quad$ Sixth, an oxidation film may prevents the occurrence of whisker. On other hand a surface diffusion of zinc can make a deficit at this film.

These stresses do not all occur simultaneously, and sometimes they offset each other, so the phenomenon is complex. We believe that if we could order them, the phenomenon would become simpler.

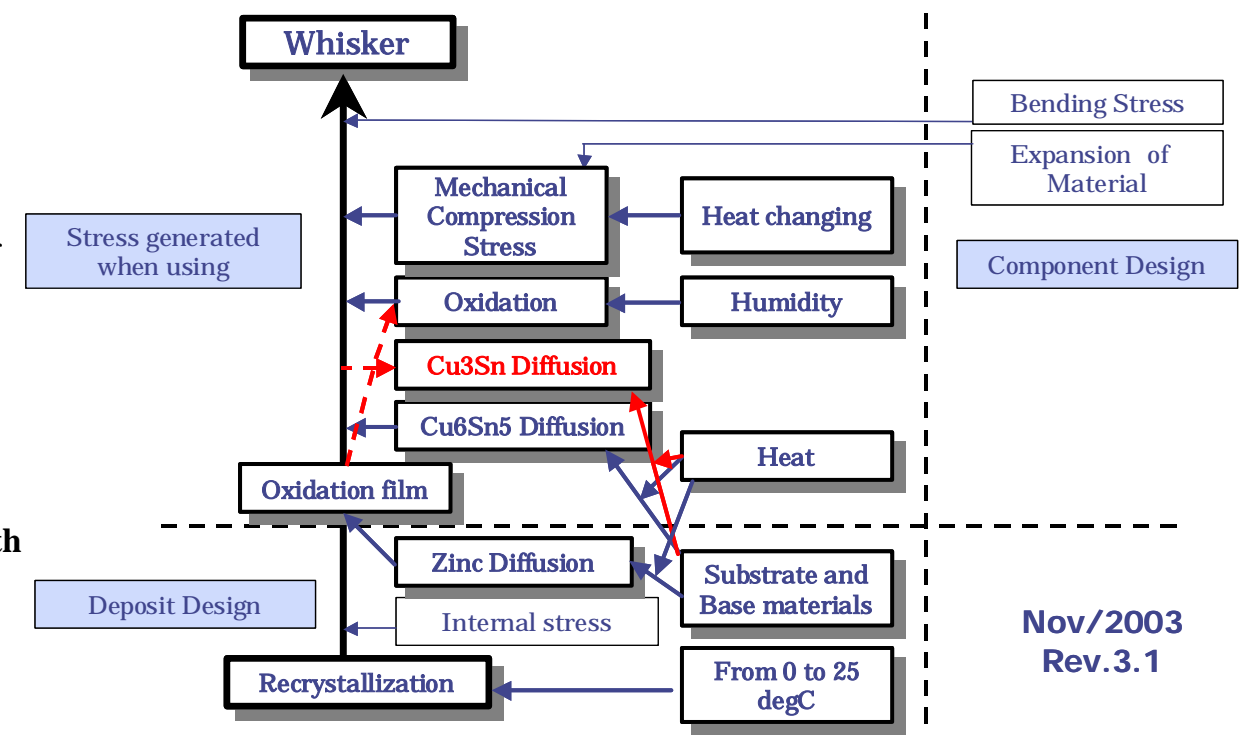




\section{Experimental}

\subsection{Experiment Method}

Table 1 shows the fundamental studies and the first acceleration studies that were carried out.

In a table, the horizontal axis shows the experiment conditions, which carried out, and the vertical axis shows the various Tin plating bath chemistry.

We supposed that electronic devices were given by the stress of a press, storage at high temperature and humidity, or a storage low atmosphere, a soldering, and a heat changing when they were used. Then, we have given to specimen a stress of the press, a high temperature and humidity, a soldering heating, a heat change, a vacuum storage, and so on after plating. Thereby, "the relation between external stress and a whisker growth" was verified. The fundamental studies were expected to run for two or more years. At this point they are about 24 months into the plan.

Next, SnA, recent Tin plating and recent alloys plating were prepared by the vertical axis. SnA plating was prepared to reproduce a whisker growth by using old type chemistry. There is also $\mathrm{Sn}-\mathrm{Pb}$ plating as a comparison.

Table 1 - JEITA Matrix

\begin{tabular}{|c|c|c|c|c|c|c|c|c|c|c|c|c|c|c|c|c|c|c|}
\hline & \multirow{2}{*}{\multicolumn{2}{|c|}{ Plating }} & \multirow{4}{*}{$\begin{array}{c}\text { Substr } \\
\text { ata }\end{array}$} & \multirow{4}{*}{$\begin{array}{l}\text { Base } \\
\text { Metal }\end{array}$} & study & \multirow{2}{*}{\multicolumn{6}{|c|}{ Fundamental Study }} & \multicolumn{6}{|c|}{ Accelerated Study } \\
\hline & & & & & & numbe & & & & & & & & 1 & 2 & 3 & 4 & 5 \\
\hline & & & & & & houre & 0 & 4000 & 4500 & 9800 & 10300 & 12300 & 4000 & 10000 & 1500 & 1500 & 4000 & 4000 \\
\hline & & Chemistry & $\begin{array}{l}\text { Thick } \\
\text { ness }\end{array}$ & & & stress & Reflow & $\begin{array}{c}\text { 30degC } \\
85 \%\end{array}$ & $\mathrm{H} / \mathrm{C}$ & RT & Vacuumed & $\mathrm{H} / \mathrm{C} 2$ & RT & RT & $\begin{array}{l}\text { 50deg } \\
\text { C50\% }\end{array}$ & $\begin{array}{l}\text { 50deg } \\
\text { C85\% } \\
\end{array}$ & $\begin{array}{l}\text { 60deg } \\
\text { C93\% }\end{array}$ & $\begin{array}{l}85 \mathrm{deg} \\
\mathrm{C} 85 \%\end{array}$ \\
\hline A & \multirow{3}{*}{ SnA } & \multirow{3}{*}{$\begin{array}{l}\text { TC :0.ON\% } \\
\text { (Bright) } \\
\text { sulfuric acid }\end{array}$} & \multirow{4}{*}{$2 \sim 3$} & \multirow{10}{*}{ Copper } & \multirow{2}{*}{\multicolumn{2}{|c|}{ Copper }} & - & Done & Done & - & - & - & Done & Done & Done & Done & Done & Done \\
\hline B & & & & & & & Done & Done & Done & - & - & - & - & - & - & - & - & - \\
\hline C & & & & & $\mathrm{Br}$ & ass & - & - & - & - & - & - & Done & - & Done & Done & Done & Done \\
\hline $\mathrm{D}$ & \multirow{5}{*}{ SnB } & \multirow{5}{*}{$\begin{array}{l}\text { TC :0.00N\% } \\
\text { (Matte) } \\
\text { sulfuric acid }\end{array}$} & & & \multirow{4}{*}{\multicolumn{2}{|c|}{ Copper }} & - & Done & Done & - & - & - & Done & Done & Done & Done & Done & Done \\
\hline $\mathrm{E}$ & & & 5 & & & & - & Done & Done & - & - & - & - & - & - & - & - & - \\
\hline $\mathrm{F}$ & & & 10 & & & & - & Done & Done & Done & Done & Done & Done & Done & - & - & - & - \\
\hline G & & & \multirow{8}{*}{$2 \sim 3$} & & & & Done & Done & Done & - & - & - & - & - & - & - & - & - \\
\hline $\mathrm{H}$ & & & & & $\mathrm{Br}$ & ass & - & - & - & - & - & - & Done & - & Done & Done & Done & Done \\
\hline 1 & \multirow{8}{*}{$-\mathrm{SnC}$} & \multirow{10}{*}{$\begin{array}{c}\text { TC :0.0ON\% } \\
\text { (Matte) } \\
\text { MSA }\end{array}$} & & & \multirow{5}{*}{\multicolumn{2}{|c|}{ Copper }} & - & Done & Done & - & - & - & Done & Done & Done & Done & Done & Done \\
\hline$J$ & & & & & & & Done & Done & Done & - & - & - & - & - & - & - & - & - \\
\hline $\mathrm{K}$ & & & & \multirow{2}{*}{ Nickel } & & & - & Done & Done & Done & Done & Done & Done & Done & Done & Done & Done & Done \\
\hline $\mathrm{K} 2$ & & & & & & & - & - & - & - & Done & Done & - & - & & & & \\
\hline $\mathrm{L}$ & & & & \multirow{2}{*}{ Copper } & & & Done & Done & Done & Done & Done & Done & - & - & - & - & - & - \\
\hline $\mathrm{M}$ & & & & & $\mathrm{Br}$ & ass & - & - & - & - & - & - & Done & - & Done & Done & Done & Done \\
\hline W & & & 10 & & & & - & - & - & - & Done & Done & - & - & & & & \\
\hline $\mathrm{x}$ & & & 10 & Copper & & & Done & - & - & - & - & Done & Done & - & Done & Done & Done & Done \\
\hline $\mathrm{N}$ & \multirow{2}{*}{ SnD } & & \multirow{2}{*}{5} & \multirow{2}{*}{ Nickel } & Chi & ip C & - & Done & Done & Done & Done & Done & - & - & - & - & - & - \\
\hline 0 & & & & & $\mathrm{Chi}$ & ip R & - & Done & Done & Done & Done & Done & - & - & - & - & - & - \\
\hline $\mathrm{P}$ & & \multirow{2}{*}{$\mathrm{Sn}-\mathrm{Cu}$} & \multirow{7}{*}{$2 \sim 3$} & Copper & & & - & Done & Done & - & - & - & Done & Done & - & - & - & - \\
\hline Q & & & & Nickel & & & - & Done & Done & Done & Done & Done & Done & Done & - & - & - & - \\
\hline $\mathrm{R}$ & & \multirow{2}{*}{ Sn- Ag } & & Copper & & & - & Done & Done & Done & Done & Done & Done & Done & - & - & - & - \\
\hline S & & & & Nickel & Cor & oper & - & Done & Done & - & - & - & Done & Done & - & - & - & - \\
\hline $\mathrm{T}$ & & $\mathrm{Sn}-\mathrm{Bi}$ & & Copper & & & - & Done & Done & Done & Done & Done & Done & Done & - & - & - & - \\
\hline U & & ום סועל & & Nickel & & & - & Done & Done & - & - & - & Done & Done & - & - & - & - \\
\hline V & & $\mathrm{Sn}-\mathrm{Pb}$ & & Copper & & & - & Done & Done & Done & Done & Done & - & - & - & - & - & - \\
\hline
\end{tabular}

\subsection{Specimen}

A new specimen was designed for this experiment. As for the Base material, copper and brass were used. Most were plated to a thickness of 2-3 microns for comparison. As for the specimen, as shown in the Figure 2, after plating, a bend, compression, and cutting were done.

Figure 2 - Specimen

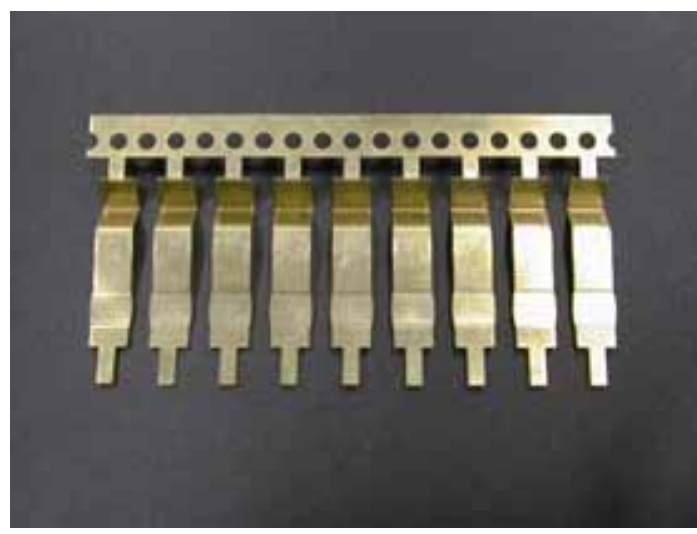




\subsection{Evaluation method}

We adopted an observation with SEM and microscope, because we need information of shapes of a whisker. The observation was done in the fixed point shown in Figure 3.

We observed them and recorded the maximum length and shapes within the observation sight.

Inspections were carried out by SEM at 1000X. The specimens were given 45 degree tilting with using SEM. So, the length data of SEM did not show absolute length.

Two methods were adopted as an evaluation method.

a) Maximum whisker length

Recording the longest whisker within the observation sight. The longest whisker at each measurement point was recorded.

b) Whisker appearance ratio

The "appearance ratio" is a percentage of incidents seen. We counted an "event" as any tin crystal or whiskers that were greater than 30 microns in length. If more than one whisker was greater than 30 microns, it was still counted as one event.

That is if 8 of the 15 cells showed a whisker (>30 microns in length) then it had a $53 \%$ rating.

Figure 3 - Observation point

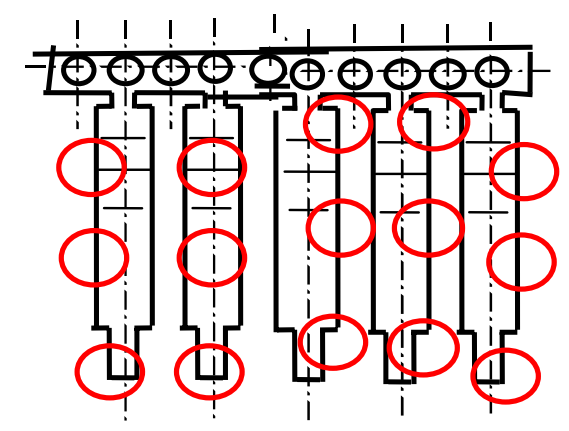

\section{Result and Discussion}

Result of Fundamental Study

Figure4 shows the result of the fundamental study on typical samples.

We summarized this result. Consequently, we found out several external stresses have influence on whisker growth that are copper diffusion, surface oxidization, and heat changing, and so on.

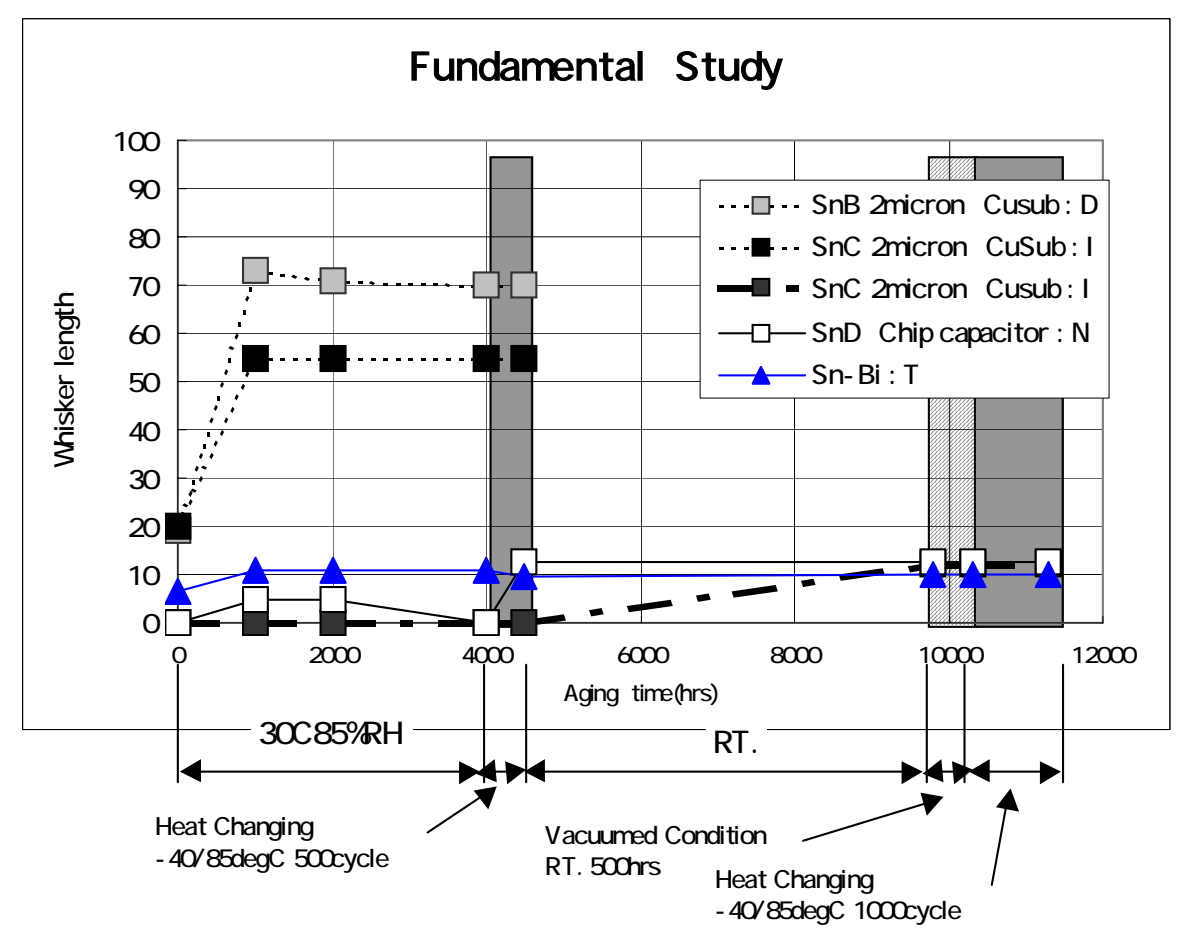

Figure 4 - Result of Fundamental Study on Typical Samples 


\subsection{Growth Mechanism by Copper Diffusion}

Figure 5 shows comparison of environment condition on a whisker growth.

As for a Tin plating on Cu substrate, that it was easy to grow whiskers more at the room temperature than high temperature was confirmed.

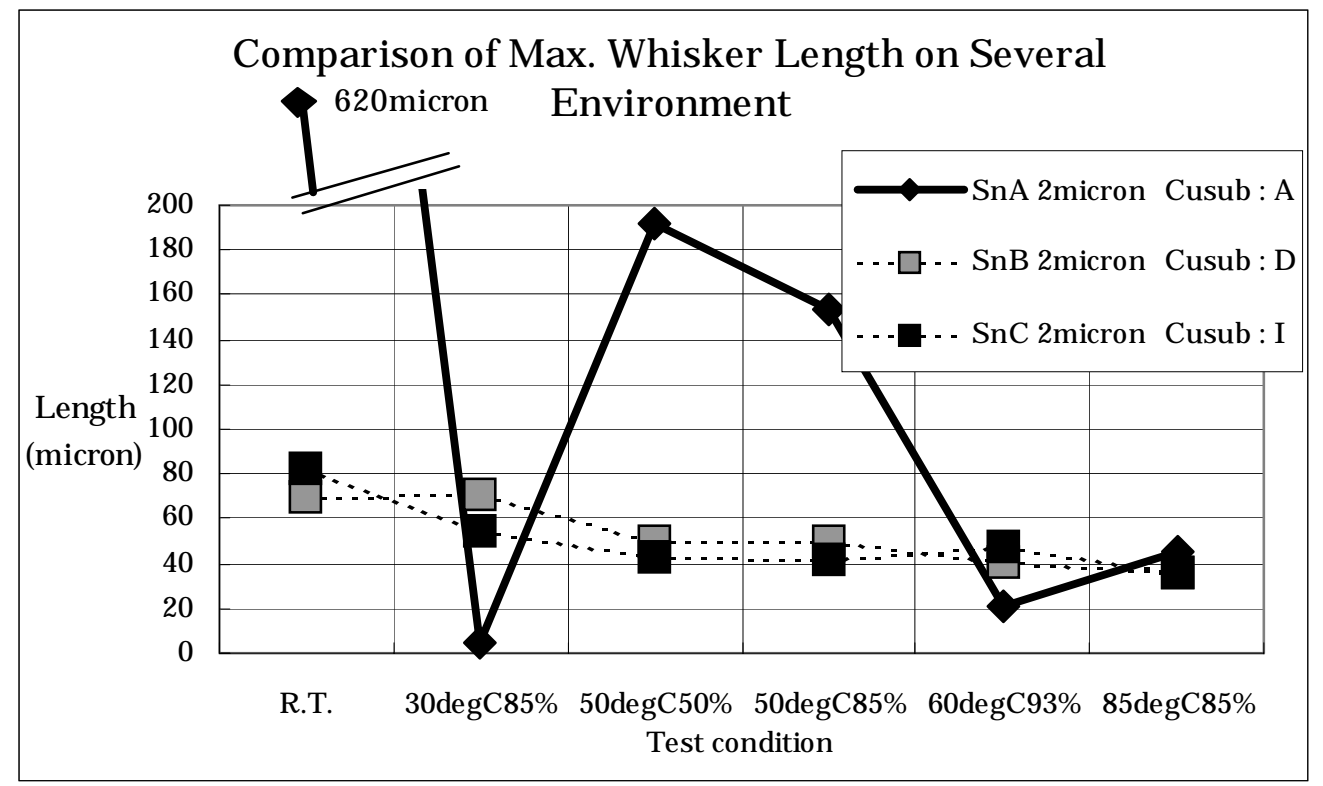

Figure 5 - Comparison of Max. Whisker Length on Several Environment

At the subcommittee, we looked at copper diffusion using XRD, believing that copper diffusion is a cause of compression stress, which causes whisker growth. (Show Figure 6)

From the result, we note that there are two inter-metallic compounds of copper: Cu6Sn5 and Cu3Sn. Moreover, we also noted that when the temperature is high, the quantity of Cu6Sn5 is increasing. However, Cu3Sn has a tendency, which is different from Cu6Sn5.

The subcommittees have considered the room temperature failure mode of whisker on $\mathrm{Cu}$ substrate as follows:

- $\quad \mathrm{Cu} 3 \mathrm{Sn}$ is grows at the same rate as Cu6Sn at high temperature, but doesn't occur at low temperature.

- A density of Cu6Sn5 is small. This means the volume is large. (Show Table 2)

- So, whisker growth occurs due to the compression stress of the changing volume.

- However, at the high temperature, Cu3Sn with low density increases the same as Cu6Sn5, and a compression stress isn't generated.

It considers from such a result that in the case of Cu diffuses in a Tin plating, Low temperature or ambient condition are optimize condition for evaluation of whisker growth.

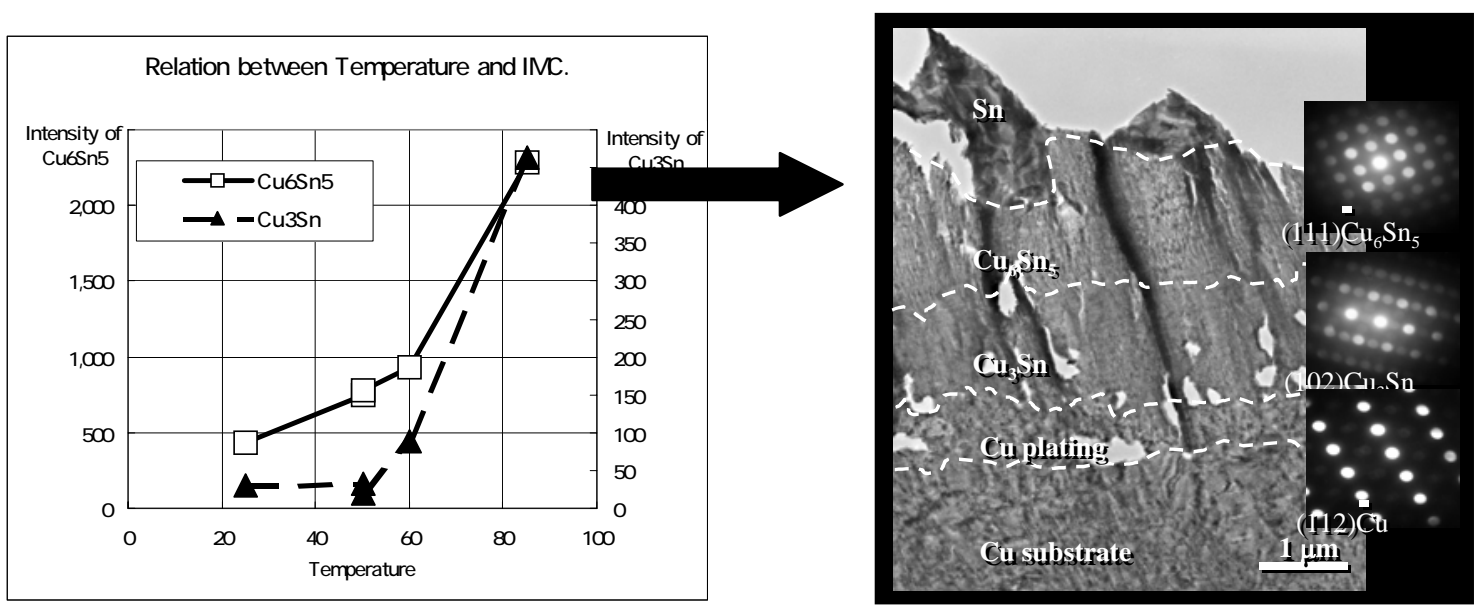

Figure 6 - Relation between Temperature and Inter-Metallic Compound and TEM photograph 
Table 2 - Density and Volume of Inter-Metallic Compound

\begin{tabular}{|c|c|c|}
\hline & Density & Volume \\
\hline $\mathrm{Sn}$ & 7.3 & 0.14 \\
\hline $\mathrm{Cu}_{6} \mathrm{Sn}_{5}$ & 8.3 & 0.12 \\
\hline $\mathrm{Cu}$ & 8.9 & 0.11 \\
\hline $\mathrm{Cu}_{3} \mathrm{Sn}$ & 11.3 & 0.09 \\
\hline
\end{tabular}

\subsection{Growth Mechanism by Copper and Zinc Diffusion and Oxidation Film}

A study was done about differences of copper and brass terminals by using above experimental method.

As a result, in case of SnA plating, at the copper material, whiskers most grow at the room temperature. However in case of a brass material, whisker grows most at 50degC. (Show Figure 7)
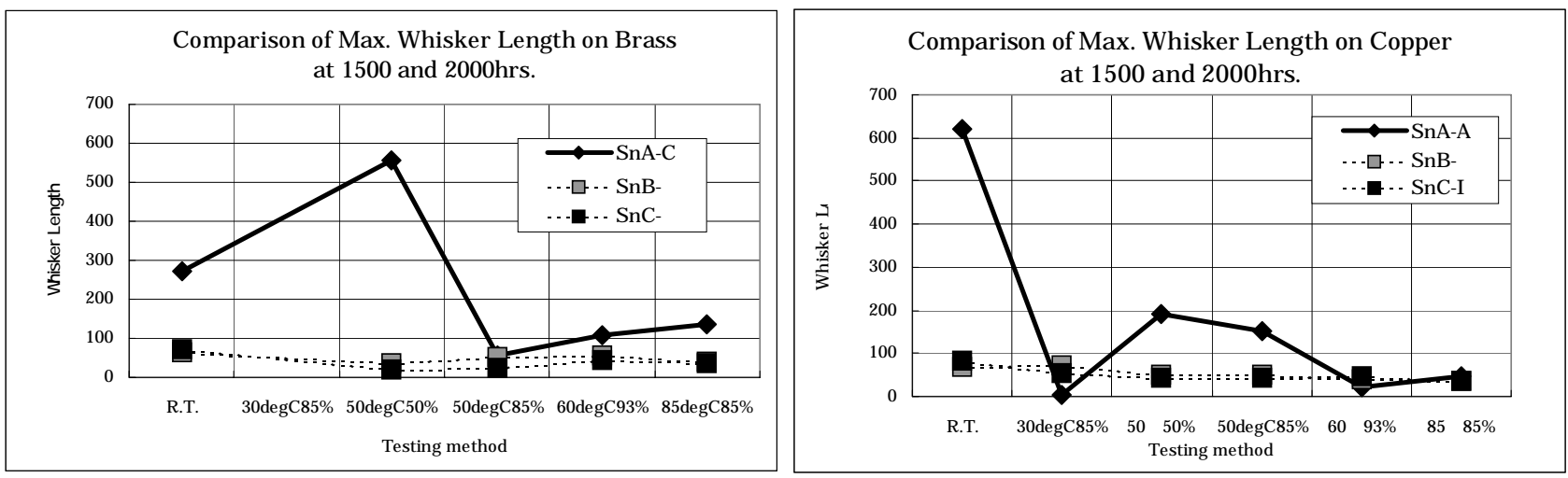

Figure 7 - Comparison of Max. Whisker Length on Brass and Copper

Therefore, it compared quantity of zinc and oxygen on the surface of the SnA brass terminals by using EPMA. (Show Figure 8)

As a result, those two things could be found.

- $\quad$ As for zinc, the detection quantity tends to increase, as temperature becomes high.

- As for oxygen, the detection quantity tends to increase, as the humidity to be experimenting on becomes high.

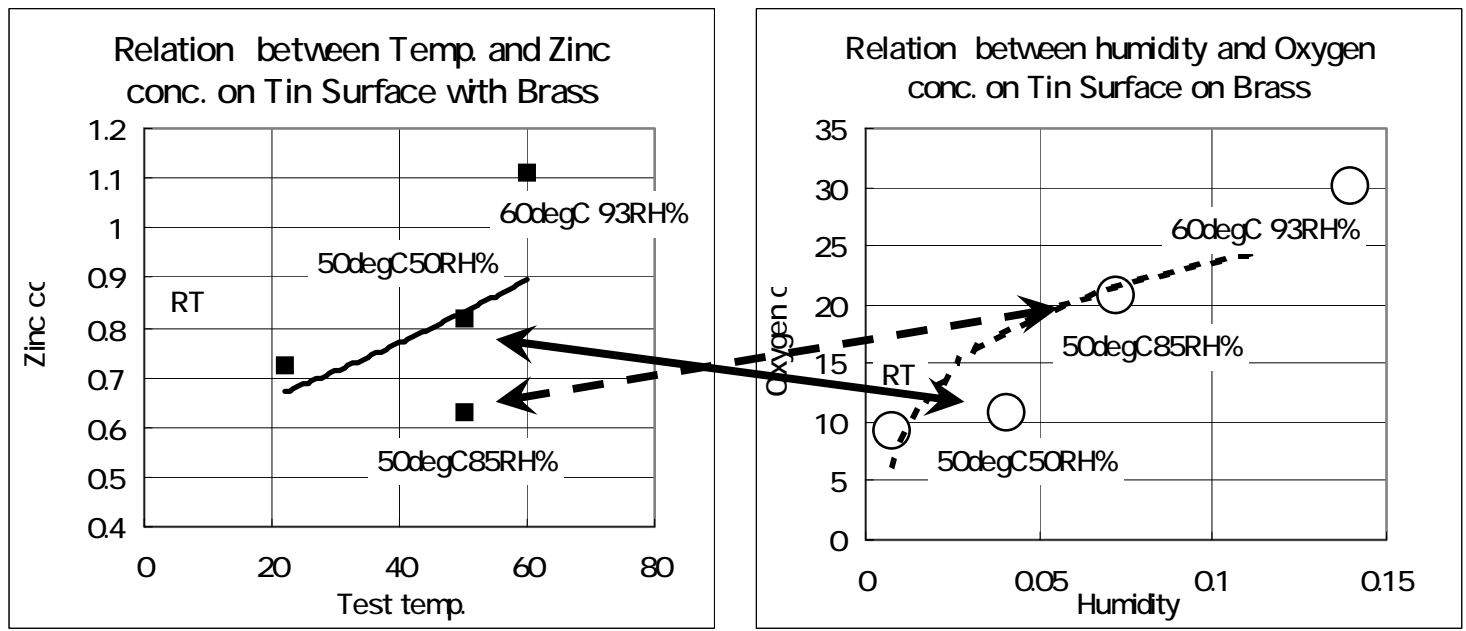

Figure 8 - Element Concentrations on Tin plating Surface

From above -mentioned result,

- When the surface oxidizes on Tin plating, " Orientation of whisker generates " is interfered with.

- On the other hand, when zinc diffuses on the surface, the deficit is occurred in the surface of the Tin plating and " Orientation of whisker generates " is occurred.

- $\quad$ Also, compression stress is generated by Cu6Sn5 diffusion.

The optimal temperature is 50degC to diffuse zinc and $\mathrm{Cu}$ at the same time. 


\subsection{Growth Mechanism by Surface Oxidization}

As for the sample of Nickel substrate plating, in conditions with the high temperature and high humidity, Whiskers were observed. (Figure 9)

As a result, in case of condition on 60degC93\%RH, it observed that a few of small Tin crystals at 4000 hours later. This means surface oxidation of Tin becomes one of failure mode of whisker. However, this time, we adopted good condition Tin plating for this study, so that only a few crystals were observed. The testing period and the acceleration coefficient are following problem.

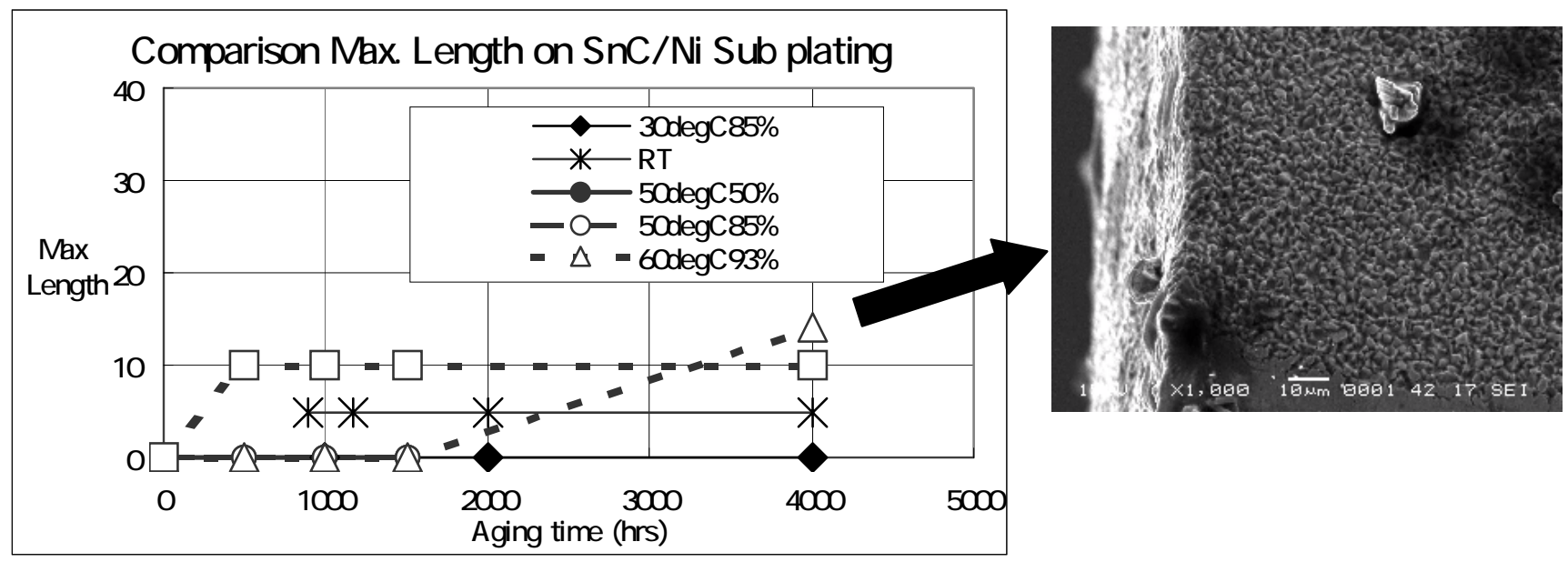

Figure 9 - Comparison Max. Whisker Length on SnC/Ni substrate plating

\subsection{Growth Mechanism by Heat Changing}

Figure 10 shows the fundamental study result that used the sample of the different base materials. Whiskers appear after a thermal cycle on ceramic base.

Whisker grows on the tin plating with copper substrate and copper base in 30degC85\%RH storage. On the other hand, as for all parts with nickel substrate, whisker could not observed in 30degC85\%RH storage.

However, as for the part with ceramic base, whisker grows after the thermal cycle to this. It seems that this whisker growth is a phenomenon that causes when compression and expansion are repeated on the plating deposit. In other words, it is explained that this phenomenon is causes with the difference of the expansion coefficients of deposit and base materials by comparison of ceramic and copper samples.

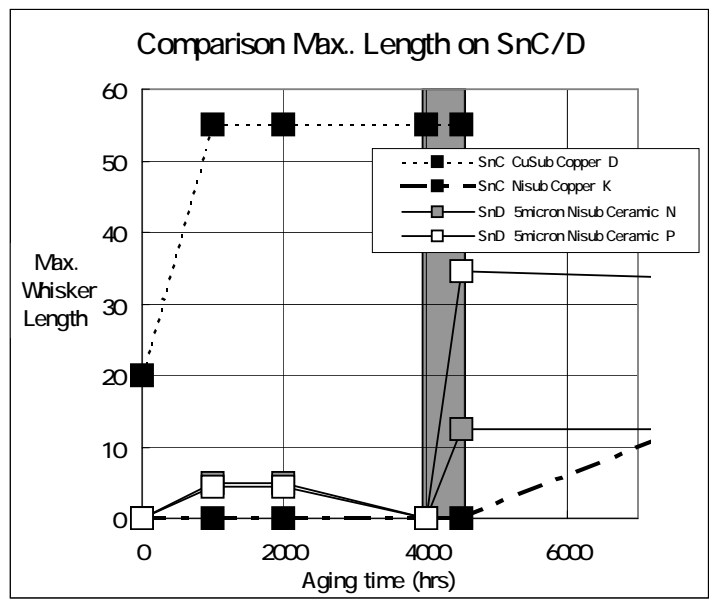

Figure 10 - Comparison Max. Whisker Length on SnC/D with several Base Materials

\section{Summary}

A lot of studies on a whisker growth were introduced from the past. However, these studies are not systematic. It may be one of reason why whisker growth is a mysterious and strange phenomenon. 
Also, We are considering that the mechanism is important to draft the testing method.

As a result, we found the following conclusion.

- As for the Whisker growth, the kind of plating chemistry has an influence mainly. However, the property of Tin is dominant and if the environment is identical, an identical tendency is gotten.

- $\quad$ As the factor of external stress, Cu6Sn5 of Cu diffusion, Zinc diffusion, high temperatures and high humidity and heat changes have an influence on the whisker growth.

The subcommittee has started to establish the draft to propose to IEC.

We hope that this study will become understanding the quality of Lead-free. Then, we hope it will be useful for the industry.

\section{References}

1) S. C. Britton: Spontaneous Growth of Whiskers on Tin Coatings 20 Years of Observation, (1974)

2) Tadashi Takemoto, Ryouhei Satoh: " Highly reliable micro-soldering technology ", Kogyo Chosakai Publishing, pp378 (1991)

3) Ryusuke Kawanaka: " Growth and Its Mechanism of Tin Proper Whiskers", JACG: Japanese crystal growth society, Vol.8 No.3\&4 (1981)

4) Ryusuke Kawanaka: Role of Lead in Growth suppression and Growth Mechanism of Tin Proper whisker," JACG: Japanese crystal growth society, Vol.10 of them No.2 (1983)

5) Toshihiro Ando, Masamutsu sibata, Seiichi Okada, Yoshikazu Namasuya: " Stress Analysis and accelerated Evaluation for Whisker under Thermal shock Stress ", Mate2000

6) Ichizo Sakamoto, Masafumi Suzuki, Osamu Hayashi,: "Lead-Free Technology for EMC terminals ", OMRON TECNICS, Vol.40 No.4, pp368, (2000)

7) Hidemi Nawafune: "Actualities and Problems of Lead-Free solder Plating", JIEP Japan Institute of Electronics Packaging the electronics loading society magazine, Vol.4, No4 (2001)

8) Susumu Arai, Norio Kaneko, Naoyuki Shinohara: " Present Situation of the Plating Technology for Lead-free Soldering", Vol 52, No. 5 The Surface Finishing Society of Japan (2001)

9) K.N.TU: ” Interdiffusion and Reaction in Bimetallic Cu-Sn Thin Films”, 1972

10) Chi-won Hwang, Keun-Soo Kim, Katuaki Sugamuma, "Interface in Lead-Free Soldering” J.Electron Mater. (2003)

11) P.J.T.L. Oberndorff, M. Dittes and L. Petit: “Intermetallic formation in relation to tin whiskers”, IPC/Soldertec lead-free conference in Brussels, 2003

12)R.M.Fishier, L.S.Darken and K.G.Caroll: “Accelerated growth of tin whisker”, ACTA METALLURGICA, Vol.2, May 1954

13) Irina Boguslavsky and Peter Bush: Recrystallization Principles Applied to Whisker Growth in Tin, IPC

SMEMA Council APEX 2003 